\title{
Raquel Rennó:
}

\section{Dejetos Materiais e Informacionais como Elementos Culturais}

\begin{abstract}
To reflect on waste is to think of it beyond cycles of consumption, as an integral element of cultural processes. The essay broadens the analysis of waste to speak of cultural remainders in a more comprehensive sense, including populations that exist (and have to subsist) at the margins of the official city, often through acts of reappropriation generally considered piracy. Such reappropriation is central to the informal economies whose control evades the cybernetic approaches to governance, and whose cultural logic offers a counterrationality to dominant processes of consumption. Piracy is a strong element of informal economies, and its mode of production and distribution operates through fragmentation, occurring in the interstices of the city or in an ephemeral manner in order to escape surveillance. Strategies of evasion and the fluidity of the market of illegal goods, the ephemeral appropriation of space by street peddlers, by garbage collectors and inhabitants of residual spaces offers a broader view of a dynamic of info-technological recodification that is not restricted to groups of tactical media, political activists, or the terrain of digital media such as Internet and mobile telephony.
\end{abstract}

\section{Agenda}

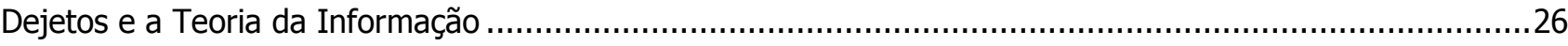

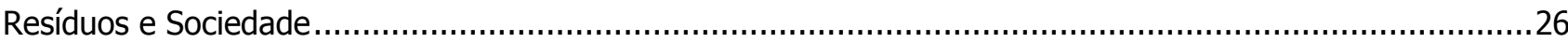

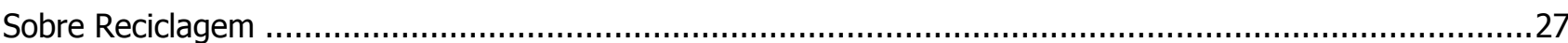

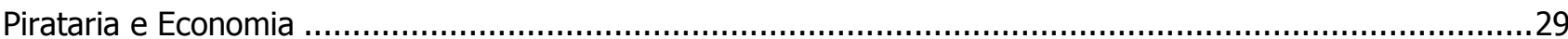

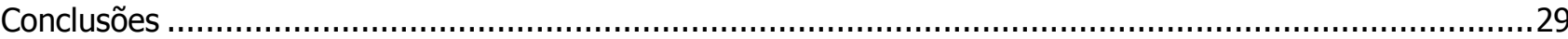

\section{Author}

Raquel Rennó

- CNPQ (Conselho Nacional de Desenvolvimento Científico e Tecnológico, Brazil), UOC (Universitat Oberta de Catalunya), ZZZINC - Investigación e Innovación Cultural

- $₫$ raquelrenno@gmail.com, 旦 http://www.raquelrenno.com, http://www.zzzinc.net

Relevant Publications:

- Do Mármore ao Vidro: mercados públicos e supermercados, curva e reta sobre a cidade? (Sao Paulo: Annablume, 2006)

- Non_sensor (Proceedings of the 13th annual ACM international conference on Multimedia, 2005) 


\section{Dejetos e a Teoria da Informação}

Os distintos modos de se apropriar da informação e objetos residuais demandam uma intensa capacidade de adaptação e de criação de novos sistemas de linguagem. Abordar os dejetos ou "aquilo que sobra" nos obriga a combinar diversos níveis de sistemas comunicacionais que vão do espaço físico propriamente dito, grupos sociais excluídos pelo poder público e privado, os resíduos deixados pelas ruas (dentro e fora das lixeiras) e que vão sendo reorganizados pelos moradores dos espaços residuais e utilizados na construção de casas, no comércio de material reciclado, até níveis que envolvem resíduos comunicacionais, fonte dos moradores de favela que fazem o gato, a gambiarra ${ }^{1}$, desviando o curso previsto dos fluxos operantes na cidade. O próprio trabalho de pesquisa para analisar estes fenômenos envolve a coleta e a combinação de elementos aparentemente distantes, fazendo uso de teorias que devem combinar o novo, revisando o que já foi estabelecido, sem poder pertencer a nenhuma estrutura rígida ou previamente estabelecida em sua completude.

Dentro da tradição da Teoria da Informação, Wiener $^{2}$ pautou a teoria cibernética na idéia de controle; o nome cibernética vem da palavra grega kubernetes, que significa piloto. Nesse sentido, tanto seres vivos quanto máquinas lutavam constantemente contra a tendência à entropia. Para ele a informação deveria ser medida pela capacidade que havia na transmissão de vencer a tendência natural à entropia, isto é, à dispersão da energia (e de informação). Wiener sabia do paradoxo que isso impunha, já que a informação de maior rapidez de compreensão (de menor dispersão) e de menor complexidade carrega menor taxa informativa. Mesmo pontuando que a entropia não pode ser considerada a priori como algo negativo, citando o exemplo da dispersão da energia solar como possibilitadora da existência da vida na Terra, a visão ainda era de um sistema de input e output (e conseqüente feedback) onde o dentro e fora do sistema estavam bem definidos. Ele apontava que a informação era o modo de permutar com o mundo

1 Termo que deixa de designar apenas a rampa de luzes no palco e passa a significar no Brasil serviço elétrico malfeito, improvisado, especialmente com a finalidade de obter energia elétrica de maneira illegal.

2 Proposta desenvolvida no decorrer do livro Cibernética $e$ Sociedade. São Paulo: Cultrix, 1993. exterior e se adaptar a ele, mas foi apenas a partir do trabalho de Maturana e Varela que se propõe a idéia de mundo exterior como algo não homogêneo e dependente das possibilidades de compreensão e percepção de cada ser vivo, assim como as trocas entre organismo e sistema alteram ambos. A dispersão da informação é parte da troca, e elementos que antes poderiam ser considerados não-partícipes de um sistema (resíduos) são apropriados por outros, reconstruindo estruturas, assumindo novas funções e em muitos casos alimentando posteriormente o próprio sistema de onde foram excluídos. Wiener sabia que a flexibilidade em adaptar-se às alterações no ambiente permite a expansão de organismos vivos e, conseqüentemente deveria servir de modelo para as máquinas a serem desenvolvidas. Sendo assim, não se pode confundir a teoria do controle como mero fator de regulagem, mas sim um elemento que possibilitaria a aprendizagem ao alterar sistemas de desempenho.

A idéia de resíduo, de dejeto tem a ver com o ruído, algo que está fora de um sistema codificado. Quanto mais energia se produz, mais fragmentos são gerados. Deste modo, a medida da entropia é um modo de se mensurar também o nível de produção de energia. Mais que isso, a maior capacidade de absorção do ruído é um fator que possibilita a complexificação de um sistema. Essa tarefa demanda ainda mais energia e conseqüentemente, maior a entropia.

Dentro de um sistema social muitas vezes o que se considera residual é associado a algo fora de lugar, fora da norma, algo que não pertence mais a uma estrutura e que está disponível para reutilização. Apropriar-se de informação, espaços e objetos que surgem aleatoriamente tem a ver com a capacidade de adaptação de um indivíduo ou grupo, ainda que essa adaptabilidade seja por vezes fruto de uma situação de emergência e carência extremas. É um trabalho subversivo ou da contra-racionalidade como propõe Santos, porque está na contramão do processo homogêneo de consumo. Não segue as normas previstas "de cima para baixo". Ao mesmo tempo, por não pertencer mais a nenhum sistema organizado é instável, móvel, um incômodo na cidade. Uma situação de potencialidade e instabilidade, mas também de disponibilidade.

\section{Resíduos e Sociedade}

A possibilidade de transformação na cultura se dá pelo choque entre elementos de sistemas distantes e pela incorporação ou reincorporação do residual, 
gerando um mosaico, um conjunto complexo que evidencia novos usos de vários elementos. Esse processo é claramente mais complexo e possível em culturas do excesso, onde a combinação de elementos múltiplos e distintos é parte do mecanismo de construção de sistemas. O conforto traria uma certeza de uma permanência simbólica que os excluídos não possuem.

É preciso compreender em que medida a residualidade gerada pela constante exclusão e ignorância em relação ao reaproveitamento de materiais e organização dos grupos sociais periféricos é um processo que impede que se crie a necessária elasticidade cognitiva da qual se beneficiariam tanto "excluídos" quanto "excludentes". Tampouco serviria cair em diferenciações das "minorias" ou de grupos "menos favorecidos" como um modo de conhecimento que não reconhece.

Os movimentos na sociedade que buscam excluir os economicamente menos favorecidos, os imigrantes ou quaisquer grupos que não sejam considerados parte da sociedade chamada "oficial" (que são tratados como dejetos e que ao mesmo tempo trabalham diretamente com a coleta e reciclagem informal do lixo), criam não somente um problema a estas pessoas que se vêem incapazes de se integrarem, mas implicam também na alienação do grupo que exclui. Não se trata de evitar a construção dos resíduos, o que seria impossível. Trata-se de tomar consciência do processo de criação do lixo para que ele possa ser recuperado de modo criativo e não seja somente fruto de um ciclo de consumo, mas da cultura. Flusser ${ }^{3}$ diz que a história humana não é uma linha linear que vai da natureza em direção à cultura, "mas um círculo que gira da natureza à cultura, da cultura ao lixo, do lixo à natureza e assim por diante". Por isso falar de dejetos é retomar na análise um elemento que é parte dos processos culturais.

Desta forma, há a coexistência da aceleração do capital mas que ao mesmo tempo encontra no espaço local e virtual tanto seu modo de concretude quanto sua resistência. $O$ espaço torna-se um objeto de consumo descartável, mas também é apropriado e reconfigurado por aqueles que não podem participar de seu consumo. Os modos como os sem-teto, favelados (no caso dos resíduos físico) e os hackers e ciberativistas (no caso dos resíduos informacionais) transitam pelo espaço são também possui-

3 FLUSSER, Vilém. O mundo codificado. Trad. Raquel AbiSamara. Sao Paulo: Cosac e Naify, 2007, pp-60-61 dores de uma fragmentação e possibilidade de adaptação que põem em xeque as estratégias velozes de ocupação do capital. Se há o resíduo artificialmente criado pelo "ciclo de vida do produto" em Marketing, e os discursos lineares e "eficientes" da publicidade, há os resíduos culturais produzidos por sociedades onde o excesso e a grande quantidade de combinações possíveis nos processos culturais são responsáveis pelas apropriações tanto dos "restos obsoletos" do mercado quanto dos resíduos imateriais que o contato entre sistemas distantes oferece. Este processo cria possibilidades de vida emergentes com resultados estéticos que sobrepassam o âmbito artístico, combinando o uso do espaço com meios tecnológicos, comunidades residuais com grupos de mídia tática, a gambiarra de luz com os warchalkers ${ }^{4}$. Estas apropriações são exemplos flagrantes do uso da tecnologia de um modo subversivo, não associadas a um elemento elitista e invariavelmente conectado ao mercado que lança os "melhores e mais potentes" com cada vez maior rapidez.

A apropriação dos dejetos por parte dos migrantes, imigrantes ou outros grupos sociais que não encontram seu espaço na cidade racional encobre questões que vão muito além das fragilidades econômicas e legais que enfrentam. Resíduos geográficos, materiais, possuem um valor simbólico que tem a ver com uma resistência à lógica de consumo e ordenação. A miséria, a falta de apoio, tornam mesmo os indivíduos que estão à margem do sistema tradicional de consumo produtores em potencial, que têm de apreender o espaço e seu entorno para daí tirar o que necessitam. Seu deslocamento constante torna essa capacidade de adaptação a contextos distintos ainda mais urgente $\mathrm{e}$ aguçada. Por não possuírem "direito à cidade" estão, como apontado anteriormente, à margem do tempo compartimentado, estruturado. Recolhem e recuperam pouco a pouco o lixo que vêem espalhados pelas ruas, nos depósitos de lixo ou mesmo nos sacos de lixo, que são abertos e separados por eles.

\section{Sobre Reciclagem}

Nas últimas décadas, o conceito de reciclagem tem se tornado uma preocupação, ainda que as ações efetivas nesse sentido sejam menos efetivas do que se propõe. Por um lado, a cidade "oficial" continua

4 Grupos que se organizam para detectar e informar locais onde há conexão de Internet sem senha para acesso que esteja disponível à apropriação. 
gerando mais lixo, seja entre os habitantes ou nas indústrias, os maiores produtores de dejetos tóxicos. Enquanto países como Estados Unidos relutam em se comprometer ativamente em reduzir a poluição e o lixo (ainda que seja um dos maiores produtores mundiais nessa área), países da Europa central transferem suas indústrias consideradas de alto risco e muito poluidoras para países economicamente de Terceiro Mundo, que não somente as recebe como ainda disputam entre si o direito a possuí-las em seu território. ${ }^{5}$

Em São Paulo o lixo que se coleta de modo seletivo e que pode ser reciclado não passa de $4 \%$ do total. Ainda assim, o trabalho de reciclagem (principalmente de alumínio) no Brasil é alto, devido à formação de cooperativas com boa gestão, ao alto valor do material como sucata, ao trabalho de catadores de lixo e ao comércio informal de reciclagem já que sua subsistência provém em grande parte da mesma fonte: o lixo. Um levantamento realizado pelo setor mostra que entre 2000 e 2005 a participação de condomínios e clubes na coleta de latas usadas passou de $10 \%$ para $24 \%$. As latas de alumínio se tornaram o carro-chefe da reciclagem no país. 0 Brasil é há 5 anos o líder mundial em reciclagem de alumínio (96,2\%, segundo a ABAL - Associação Brasileira do Alumínio).

No momento em que a reciclagem de alguns materiais começa a adquirir valor comercial, representa uma possibilidade de renda para os moradores de favelas e espaços residuais na América Latina e África. Este processo, no entanto, não possui o status glorificado que se observa em documentários educativos sobre a importância de se diminuir e reaproveitar o lixo. Constitui um trabalho quase ilegal, sem nenhum tipo de direito trabalhista e de alto risco. 6

5 Uma das disputas atuais mais comentadas é a que se estabeleceu entre Argentina e Uruguai, que envolveu desde manifestações populares até conflitos diplomáticos, para decidir que país acolheria uma fábrica de celulose de capital espanhol em áreas próximas ao rio de La Plata, que divide os dois países.

www.cpcmercosur.gov.ar/cpcprensa/2006/200612/20061215.htm

www.elcorreo.eu.org/esp/article.php3?id article $=6669$

6 Folha de S. Paulo, 22/9/2005: "Catadores de lixo serão expulsos de Pinheiros": A Coopamare (Cooperativa de Catadores Autônomos de Papel, Aparas e Materiais Reaproveitáveis) será despejada da parte de baixo do viaduto Paulo 60, em Pinheiros (zona oeste), local que ocupa desde 1989. Os catadores foram notificados neste mês, mas disseram que não irão sair. $O$ despejo gerou polêmica e mobilizou
Podemos encontrar por todo o Brasil casos de discriminação contra os catadores de lixo. Mesmo quando há um plano de reciclagem de materiais, ele é muitas vezes imposto sem a inclusão das pessoas que já trabalhavam com o lixo. Em Goiânia7 foi denunciado que catadores de lixo estavam sendo espancados pela polícia como modo de impedir seu trabalho e, principalmente, sua organização como cooperativa. A pressão sobre a importância ecológica da reciclagem e 0 „,crescimento sustentável" faz com que haja preocupação com o lixo material, mas se exclua os que o vêm utilizando como modo de subsistência. Esta rede social passa a ser o resíduo do resíduo.

Por detrás de todas as implicações econômicas que envolvem a recuperação e coleta informal de lixo há um processo cultural importante. Trata-se de um processo de tradução constante que se intensifica com a necessidade de realizar combinações inusitadas com o que está disponível. Por um lado, o lixo é abundante, por outro, como fazer para que possa ser reinserido no sistema e em que sistema(s)? As possibilidades são inúmeras, já que não há lei que defina o uso destes materiais nem o modo de interação destas pessoas. Estar esquecido pela cidade oficial passa a ser vivenciado a partir de maiores possibilidades de escolha. As garrafas PET podem ser recicladas, usadas para a construção de moradias, levar água ou guardar moedas e objetos pequenos que se encontram pela rua. Uma caixa de papelão pode ser cobertor, casa ou armário. Misturar-se ao mercado de rua semanal pode ser a possibilidade de revender peças recuperadas do lixo, ou a manta por sobre onde se vende a mercadoria pirata pode transformar-se em trouxa de roupas quando a fiscalização policial se aproxima.

Os movimentos na sociedade que buscam excluir os economicamente menos favorecidos, os imigrantes ou quaisquer grupos que não sejam considerados parte da sociedade chamada "oficial”, criam não somente um problema a estas pessoas que se vêem incapazes de se integrarem, mas implicam também na alienação do grupo que exclui. Não se trata de evitar a construção do lixo, o que seria impossível.

alunos e professores da FAU (Faculdade de Arquitetura e Urbanismo da USP), que realizam aulas no local e têm o trabalho da cooperativa como alvo de pesquisa. Para o professor da FAU e urbanista João Whitaker, o prefeito José Serra (PSDB) retomou uma política de „expulsão da população pobre das áreas mais ricas, do centro expandido". A cooperativa reúne 56 cooperados e beneficia uma média de 130 toneladas de material para reciclagem por mês.

7 www.midiaindependente.org/pt/blue/2006/12/369276.shtml, 3 de dezembro de 2006. Acessado em agosto de 2007. 
Trata-se de tomar consciência do processo de criação do lixo para que ele possa ser recuperado de modo criativo e não seja somente fruto de um ciclo de consumo, mas da cultura. Flusser (2006:60-61) diz que a história humana não é uma linha linear que vai da natureza em direção à cultura, "mas um círculo que gira da natureza à cultura, da cultura ao lixo, do lixo à natureza e assim por diante". Por isso falar do resíduo é retomar na análise um elemento que sempre foi parte dos processos culturais.

A negação da importância do lixo implica em questões éticas, estéticas e é de busca utópica, que só pode ser colocada em prática a partir de ideologias totalitárias. Essa cegueira, embora não se trate de um fato recente, acaba sendo apropriada pela filosofia de mercado atual, onde a competição compreendida como algo natural gera uma hierarquia que justifica ações continuamente excludentes tanto em termos sociais quanto materiais.

\section{Pirataria e Economia}

É evidente que o excesso de produção só pode ser sustentado a partir do estímulo do consumo, onde a publicidade é o braço mais forte das estratégias de mercado. No entanto, o contingente de pessoas que não podem participar desta dinâmica é enorme. De aí vem por um lado as falsificações, os produtos piratas. Mas o mais significativo neste panorama é como a pirataria representa para muitos um modo de sobrevivência. O Brasil é considerado o quarto pais no ranking da pirataria, só ficando atrás da China, Rússia e Índia. Não por coincidência estes são os países que compõem o grupo dos principais países emergentes economicamente no mundo (o chamado BRICs). A pirataria é um braço forte da economia informal e seus modos de produção e distribuição operam pela fragmentação, ocorrem nos interstícios da cidade ou de modo efêmero para poderem sobreviver à fiscalização.

Desta forma, há a coexistência da aceleração do capital, como mencionada por autores como Santos (2002a), mas que ao mesmo tempo encontra no espaço local tanto seu modo de concretude quanto sua resistência. O espaço torna-se um objeto de consumo descartável, mas ao mesmo tempo ele é apropriado e reconfigurado por aqueles que não podem participar de seu consumo. Os modos como os sem-teto, favelados, imigrantes ilegais, ciganos transitam pelo espaço são também possuidores de uma fragmentação e possibilidade de adaptação que põem em xeque as estratégias velozes de ocupação do capital. Se há o resíduo artificialmente criado pelo "ciclo de vida do produto" em Marketing, e os discursos lineares e „eficientes" da publicidade, há os resíduos culturais produzidos por sociedades onde o excesso e a grande quantidade de combinações possíveis nos processos culturais são responsáveis pelas apropriações tanto dos "restos obsoletos" do mercado quanto dos resíduos imateriais que o contato entre sistemas distantes oferece. Este processo cria possibilidades de vida emergentes com resultados estéticos que sobrepassam o âmbito artístico, combinando o uso do espaço com meios tecnológicos, comunidades residuais com grupos de mídia tática, a gambiarra de luz com os warchalk$e r s^{8}$. É importante propor estas possibilidades, que podem ser desenvolvidas em um próximo estudo, para que as tecnologias não sejam compreendidas logo de saída como um elemento elitista e invariavelmente conectado ao mercado que lança os "melhores e mais potentes" com cada vez maior rapidez.

\section{Conclusões}

A gambiarra, as estratégias de fuga e fluidez do mercado pirata, as apropriações efêmeras do espaço pelos camelôs, pelos catadores de lixo e pelos moradores dos espaços residuais oferecerem uma visão mais ampla das apropriações informacionais dinâmicas que não estão restritas aos grupos de mídia tática ou coletivos de ativistas políticos nem aos meios digitais como a Internet e a telefonia celular. É importante mostrar que estas formas de organização residuais possuem uma mobilidade constante que encontra nos sem-teto e nos imigrantes ilegais agentes de fundamental importância.

Não se trata de um otimismo em que não se percebe que nos produtos piratas e nas práticas de mercado informal se encontra um braço de um capitalismo voraz e não necessariamente sua alternativa. É exatamente por saber que nos discursos pró-identidade e anti-pirataria se ocultam interesses de contínua exploração dos grupos "excluídos" que é necessário compreender como estes discursos estão impregnados de incongruências e promessas de falsa estabilidade. Somente desconstruindo estes discursos é possível ver o que se esconde por detrás, perceber que o processo de exclusão vai se alimentando do sistema paralelo dos excluídos,

Grupos que se organizam para detectar e informar locais onde há conexão de Internet sem senha para acesso que esteja disponível à apropriação. 
gerando lixo continuamente sem aproveitá-lo de modo consciente, crítico e reestruturador.

\section{Referencias Bibliográficas}

Ferarra, Lucrécia D'Alessio. Design em espaços. Sao Paulo: Rosari, 2002.

Flusser, Vilém. O mundo codificado. Trad. Raquel Abi-Samara. Sao Paulo: Cosac e Naify, 2007.

Lynch, Kevin e Southworth, Michael. Echar a perder, una análisis del deterioro. Trad. Joaquin Rodriguez Feo. Barcelona: Gustavo Gilli, 2005.

Lotman, Iuri. La semiosferea II - Semiótica de la cultura, del texto, de la conducta y del espacio. Trad. Desiderio Navarro. Madrid: Cátedra Universidad de Valencia, 1998.
Maturana, Humberto R.; Varela, Francisco J. $A$ árvore do conhecimento. Campinas: Psy, 1987.

Maturana, Humberto R.; Varela, Francisco J. De máquinas e seres vivos: autopoiese: a organização do vivo. Porto Alegre, Editora Artes Médicas, 1997.

Santos, Milton. A natureza do espaço. Sao Paulo, EDUSP, 2002.

Wiener, Norbert. Cibernética e Sociedade - O Uso Humano de Sêres Humanos. Trad. Gita K.Ghinzberg. Sao Paulo: Cultrix, 1958. 